\title{
Effect of processing on properties of thin walled calandria tubes for pressurised heavy water reactor
}

\author{
K. Kapoor ${ }^{\text {a,* }}$, C. Padmaprabu ${ }^{\text {a }}$, S.V. Ramana Rao ${ }^{\text {a }}$, T. Sanyal ${ }^{\text {a }}$, B.P. Kashyap ${ }^{\text {b }}$ \\ a Advanced Materials Characterisation Laboratory, Nuclear Fuel Complex, Hyderabad 500062 , India \\ ${ }^{\mathrm{b}}$ Department of Metallurgical Engineering and Materials Science, Indian Institute of Technology, Mumbai 400 076, India
}

\begin{abstract}
Thin walled calandria tubes for pressurised heavy water reactors are manufactured either by seam welding of Zircaloy-4 sheets or by seamless route. In the present study, the effect of processing on the critical properties such as texture, microstructure, hydriding behaviour and residual stress for both the routes as well as the mechanical anisotropy developed due to seam welding are investigated. The properties of the seam welded tube in the fusion and adjoining region are markedly different from the base material and from the seamless tube. Residual stress measurements indicate that heat affected zone (HAZ) of seam welded tubes have longitudinal tensile residual stress and the seamless tubes have uniform compressive stress along the circumference. The phase transition in the presence of residual stresses due to thermal gradient is found to modify the texture in the HAZ. The hydride orientation and mechanical anisotropy in these regions are found to be dependent on the texture of the material.
\end{abstract}

\section{Introduction}

In the fuel channel of a pressurised heavy water reactor (PHWR), the calandria tube surrounds the hot pressure tube and isolates it from the cool heavy water moderator. The material used for this application is a zirconium based alloy with $1.5 \% \mathrm{Sn}-0.21 \% \mathrm{Fe}-0.1 \% \mathrm{Cr}$ (nominal composition of Zircaloy-4). Zirconium alloys have hexagonal close packed (hcp) crystal structure and exhibit highly anisotropic physical, mechanical and stress corrosion properties. This anisotropy, due to the preferred orientations of the grains, is a result of the thermo mechanical processing route adopted for fabrication. Fig. 1 shows the two processing methods namely seam welded (Route-1) and seamless (Route-2) routes adopted for the manufacturing of thin walled calandria tubes [1,2]. In Route-1 (old method which was followed earlier) the processing involved a hot rolling followed by three cold rolling operations. Surface machining is done after the initial hot rolling to remove the surface contaminants present in the melt. After each cold rolling, annealing and pickling are done for stress relieving and surface cleaning purposes, respectively. While in Route2 (newly developed method and currently being used) the hollow hot extruded blanks are cold pilgered in three steps with an intermediate heat treatment for stress relieving. The advantage of Route- 2 is that it involves less number of processing stages in comparison to Route-1, and hence results in higher material recovery.

During reactor operation hydrogen is absorbed into the tubes leading to the formation of hydrides. The orientation of these hydrides significantly influences the fracture properties of the material. Further, the stress gradients in the material facilitate hydrogen migration from low stress regions to locally high stress regions. This can initiate delayed hydride cracking even under low stress intensities. Cracks have been observed earlier in $\mathrm{Zr}-2.5 \mathrm{Nb}$ pressure tubes [3] in rolled joined regions due to excessive residual stresses. It is therefore 


\section{Route 1}

$\begin{array}{lc}\text { Zr-2 ingot } & \text { Zr-2 ingot } \\ \downarrow & \downarrow \\ \text { Extrude } & \text { Extrude } \\ \downarrow & \downarrow \\ \text { Heat treatment } & \text { Heat treatment } \\ \downarrow & \downarrow \\ \text { Hot roll } & \text { Cold Pilgering I } \\ \downarrow & \downarrow \\ \text { Surface grinding/Pickling } & \text { Heat treatment } \\ \downarrow & \downarrow \\ \text { Heat treatment } & \text { Cold Pilgering II } \\ \downarrow & \downarrow \\ \text { Cold roll } & \text { Heat treatment } \\ \downarrow & \downarrow \\ \text { Heat treatment (annealing \& pickling) } & \text { Cold Pilgering III } \\ \downarrow & \downarrow \\ \text { Cold roll } & \\ \downarrow & \\ \text { Heat treatment (annealing \& pickling) } & \text { Final Product } \\ \downarrow & \\ \text { Cold roll } & \\ \downarrow & \\ \text { Heat treatment (annealing \& pickling) } & \\ \downarrow & \\ \text { Break form } & \\ \downarrow & \\ \downarrow & \\ \downarrow & \\ & \\ & \\ & \end{array}$

Fig. 1. Processing methods adopted for the manufacturing of thin walled calandria tubes. necessary to understand the nature of hydride orientation and residual stress in the material due to the processing route adopted.

Welding in Route-1 produces local changes in microstructure and crystallographic texture of the tubes. These localised variations influence the mechanical anisotropy of the material. Moreover, in accidental conditions such as failure of pressure tube, calandria tube will be subjected to higher stress and plastic deformation due to leaking coolant. In this context, a thorough knowledge of crystallographic texture and the mechanical anisotropy property of the calandria tubes is indispensable for reactor applications. Towards fulfilling the above requirements a comprehensive and systematic study was carried out to investigate the effect of processing route on the properties of the thin walled calandria tubes for PHWR applications.

\section{Experimental and results}

\subsection{Tensile properties}

To get the effect of processing on the mechanical properties of thin walled calandria tubes, tensile tests were done using Zwick Universal Testing Machine, model 1476. Two specimens of $50 \mathrm{~mm}$ gauge length for each processing route were prepared from the transverse direction (TD) of the tube. The tests are performed at room temperature and the strain rate was kept at $2.6 \times 10^{-3} \mathrm{~s}^{-1}$. The tensile properties of the individual specimens are listed in Table 1. From the table it can be seen that no appreciable variation in tensile properties is observed due to the different processing route adopted. Hence using either route, the desired mechanical properties could be obtained for the reactor application of calandria tubes.

\subsection{Microstructure}

To characterize the microstructure associated with Route-1 and Route-2, metallographically prepared

Table 1

Transverse tensile properties of calandria tubes processed using Route-1 and Route- 2 at room temperature

\begin{tabular}{lllll}
\hline Material & & $0.2 \%$ Yield strength $(\mathrm{MPa})$ & Ultimate tensile strength (MPa) & Total elongation (\%) \\
\hline Route-1 & Sample 1 & 365 & 419 & 26 \\
& Sample 2 & 364 & 426 & 27 \\
& Average & 364.5 & 422.5 & 26.5 \\
\multirow{2}{*}{ Route-2 } & Sample 1 & 377 & 468 & 29.7 \\
& Sample 2 & 383 & 472 & 28.0 \\
& Average & 380 & 470 & 28.9 \\
\hline
\end{tabular}


samples are examined under polarized light using a Rechert MeF2 research microscope. Three unique regions, namely, base material (BM), heat affected zone (HAZ) and fusion zone (FZ) are identified across the weld along the circumference of the tube processed using Route-1. The BM microstructure contains equiaxed fine grains of $\alpha-\mathrm{Zr}$ with well known intermetallic $\mathrm{Zr}(\mathrm{Fe} \mathrm{Cr})_{2}$ type secondary phase particles (SPP) [4]. In the HAZ and FZ, a martensitic structure is observed. The grains are comparatively larger in the FZ than in HAZ. The microstructure developed in Route-2, called seamless microstructure, is observed to be uniform along the

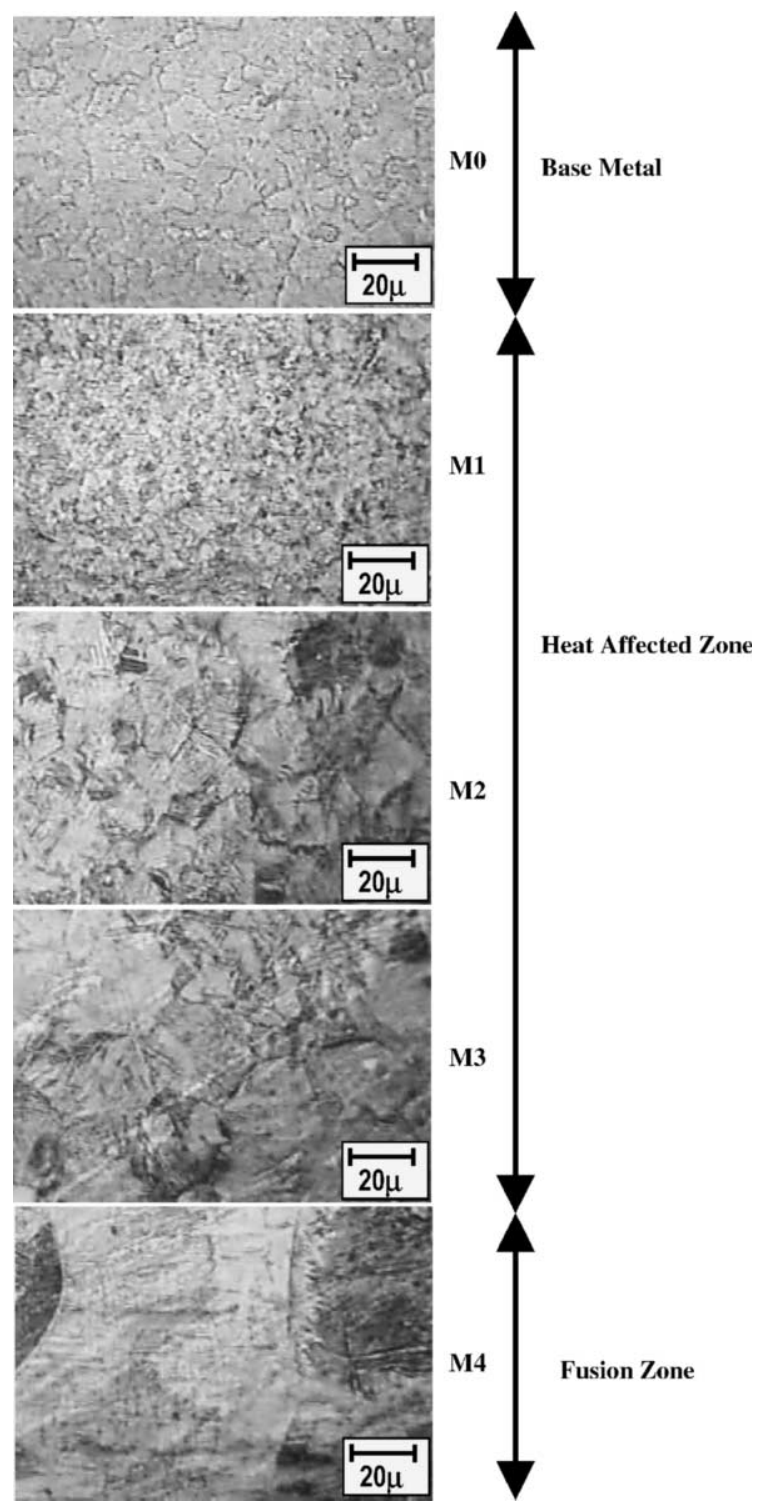

Fig. 2. Microstructural variation across the weld region in Route-1.
Table 2

Grain sizes measured from the microstructure of calandria tubes processed using Route-1 and Route-2

\begin{tabular}{llll}
\hline Material & \multicolumn{3}{l}{ Grain size $(\mu \mathrm{m})$} \\
\cline { 2 - 4 } & Radial & Transverse & Longitudinal \\
\hline Route-1 & 9.0 & 10.5 & 10.7 \\
Route-2 & 8.7 & 9.4 & 9.1 \\
\hline
\end{tabular}

circumference of the tube. The grain structure, SPP size and its distribution are found to be identical to that of BM. Fig. 2 illustrates the microstructural variation across the weld region. Table 2 gives the measured grain sizes of the calandria tubes processed using the two different routes.

\subsection{Crystallographic texture}

To understand the influence of processing on the texture development, quantitative texture analysis using Rigaku Dmax 2000 X-ray diffractometer was carried out. The instrument is equipped with a horizontal goniometer for texture measurements. The radiation used was $\mathrm{Cu} \mathrm{K} \mathrm{K}_{\alpha}(\lambda=1.54 \AA, 40 \mathrm{kV}, 30 \mathrm{~mA}$ with Ni filter).

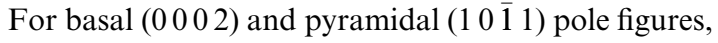
three specimens each from BM, HAZ and FZ in Route-1 and one specimen for seamless in Route- 2 were prepared from the tube outer surface. The specimens were $12 \mathrm{~mm}$ in width along the TD and $25 \mathrm{~mm}$ in length along the tube rolling direction (RD). In this specimen configuration the tube normal direction (ND) coincides with the center of the pole figure. Specimens were subsequently ground flat, polished and etched.

Pole figures of the specimens were obtained using the Schultz reflection technique [5]. Bunge et al. described the basic principle of this technique [6]. In reflection technique the X-ray source and the goniometer were made to face the same side of the specimen surface. A schematic sketch of reflection geometry is illustrated in Fig. 3. In this geometry the three axes, namely specimen tilt axis $A$, specimen rotation axis $B$ and the goniometer axis $C$, were aligned mutually orthogonal to each other. An optical focusing system was used for the alignment of axes. Angle $\alpha$ refers to specimen tilt about axis $A, \beta$ refers to specimen rotation about axis $B . \gamma$ oscillation represents reciprocating motion in the specimen plane which is at an angle $45^{\circ}$ with respect to axis $A$. The defocusing correction was carried out using a powder specimen as usual. Fig. 4 shows the pole figures of basal

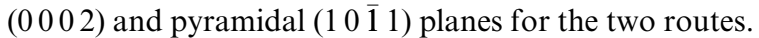

From Fig. 4(a) and (b) it can be seen that the pole figures of BM and Route- 2 are identical and show bimodal basal pole texture oriented towards $30-40^{\circ}$ in TD-ND plane. This basal pole texture corresponds to

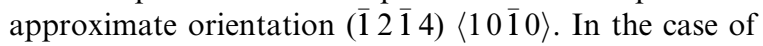




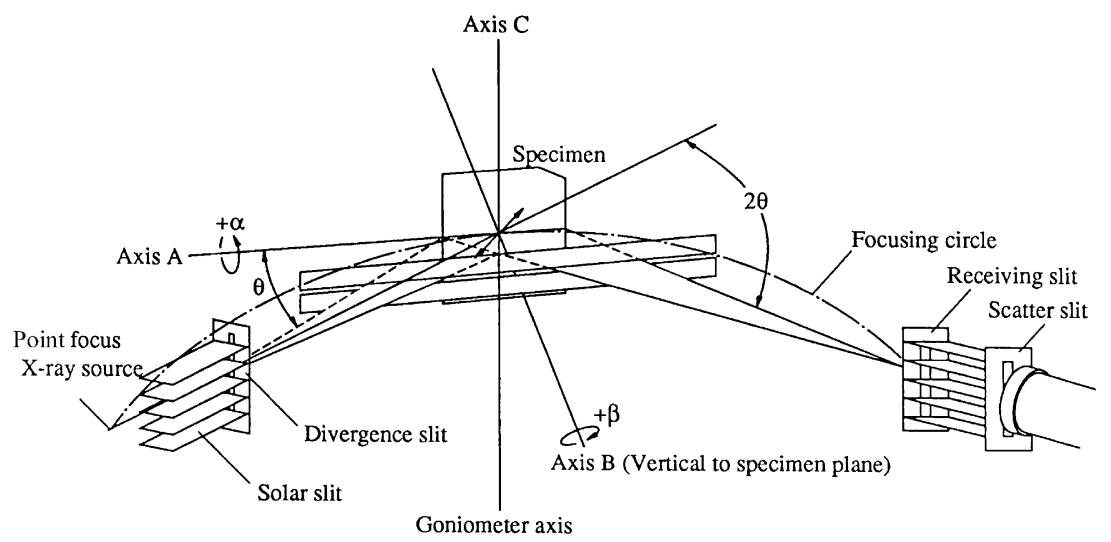

Fig. 3. Functional diagram of Schultz reflection geometry.

(a)

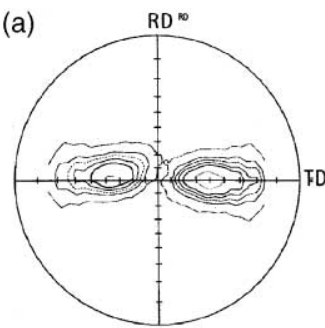

(e)

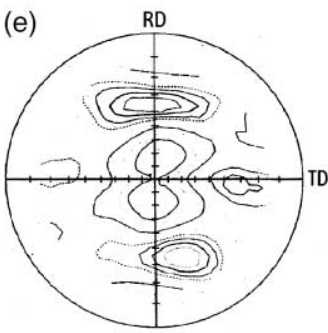

(b)

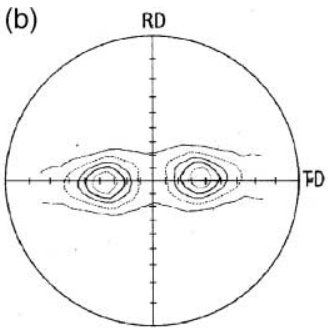

(f)

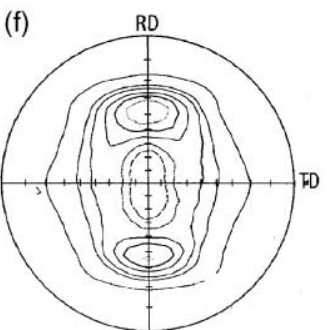

(c)

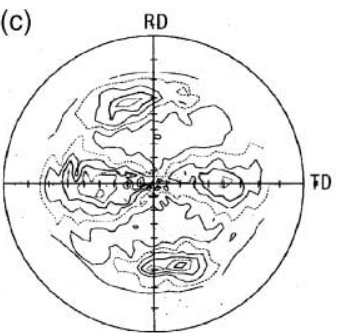

(g)

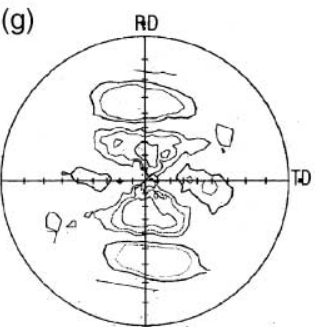

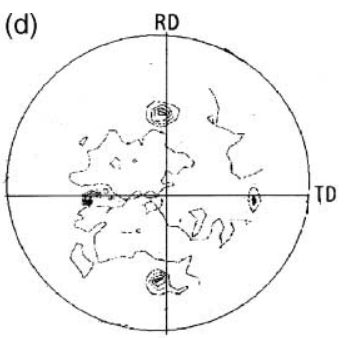

(d)

(h)

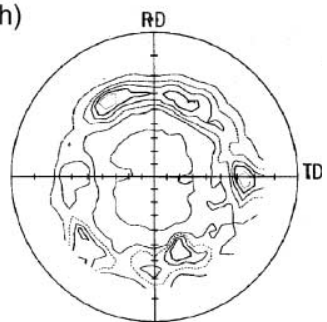

Fig. 4. Texture in the tubes processed using Route-1 and Route-2. (0 000 2) Pole figures: (a) seamless, (b) BM, (c) HAZ, (d) FZ. (1 011 1) Pole figures: (e) seamless, (f) BM, (g) HAZ and (h) FZ.

HAZ (Fig. 4(c)), the relative intensity of the basal pole is found to be decreased. The orientation is distributed towards $60^{\circ}$ in RD-ND plane. Additionally, there is a distribution towards $40-50^{\circ}$ in TD-ND plane, which corresponds to the orientations $(\overline{1} 2 \overline{1} 2)\langle 1 \overline{2} 13\rangle$ and (1) 123$)\langle 10 \overline{1} 0\rangle$ respectively. The maximum intensity of (10 1 1) pyramidal poles is found to be distributed around $50-60^{\circ}$ in ND-RD plane in both $\mathrm{BM}$ and Route-2 tube material (Fig. 4(e) and (f)). In HAZ there appeared a distribution of (10 11$)$ poles in ND-RD plane around $0-70^{\circ}$ as well as in ND-TD plane around 30-60 (Fig. 4(g)). In FZ, the $(10 \overline{1} 1)$ texture is more complex and is difficult to interpret (Fig. 4(h)). However, the relative intensity of the pole is found to be close to the intensity of random powder sample.

\subsection{Residual stress}

The $\mathrm{X}$-ray residual stress is measured using the Stress Tech X-stress 3000 equipment. The equipment consists of a goniometer with an X-ray source and a compact high voltage cum cooling system. The X-ray source used is $\mathrm{Cr} \mathrm{K}_{\alpha}(\lambda=2.29 \AA)$ radiation, with two position sensitive detectors to obtain the full X-ray diffracted peak in a single exposure. The goniometer is capable of giving inclination, rotation, vertical movements and oscillation.

The surface residual stresses are measured using the multi-exposure side-inclination technique. In this technique the peak mid position is measured by curve fitting using Pearson IV method provided as an in-built routine. The shift in the peak position is determined with 
change in inclination angles. The residual stress is determined using the following relationship:

$\sigma_{\phi}=-\left\{\frac{E}{(1+v)}\right\} \cot \theta \frac{\mathrm{d}(\Delta 2 \theta)}{\mathrm{d}\left(\sin ^{2} \psi\right)}$,

where $\sigma_{\phi}$ is stress in the direction $\phi, E$ is the elastic modulus, $v$ is poisson ratio, $\Psi$ is the inclination angle measured in direction $\phi$ and $\theta$ is Bragg's diffraction angle.

These stresses are measured in the two rotation angles to obtain the longitudinal and transverse stresses.

A sample of length $500 \mathrm{~mm}$ is taken for each route. The residual stress was measured without electro polishing the sample because the surface finish itself was sufficient for the measurement. Zirconium (1 $0 \overline{1} 4)$ plane $\left(2 \theta=157.5^{\circ}\right)$ is used for the measurement. To get a good correlation, measurements were made at minimum of $4^{\circ}$ (each in positive and negative) inclination angles. An oscillation of $\pm 10^{\circ}$ was given in $\phi$ direction and $\pm 5^{\circ}$ in $\psi$ direction to take care of the texture. Stress-free zirconium powder sample was used for calibration purposes. Residual stress measurements were carried out at three equally spaced locations separated by an angular displacement of $45^{\circ}$ along the circumference of the tube processed using Route-2. In case of Route-1, across the weld region the locations are selected at weld center line (WCL), 2, 4, and $6 \mathrm{~mm}$ from the WCL and the BM (far from WCL). Fig. 5 shows the typical 'd' vs ' $\sin ^{2} \psi$ ' plot obtained from the X-ray residual stress measurement. Fig. 6(a) and (b) shows the distribution of residual stress along the circumference of the calandria tubes processed using Route- 1 and Route- 2 respectively.

The residual stress across the weld region is found to be non-uniform. The nature of longitudinal residual stress near the weld region (about $4 \mathrm{~mm}$ from WCL) changes from compressive to tensile, although the magnitude of tensile residual stress is found to be low. Though the transverse stress is compressive in nature, the stress in HAZ moves towards tensile (i.e. less
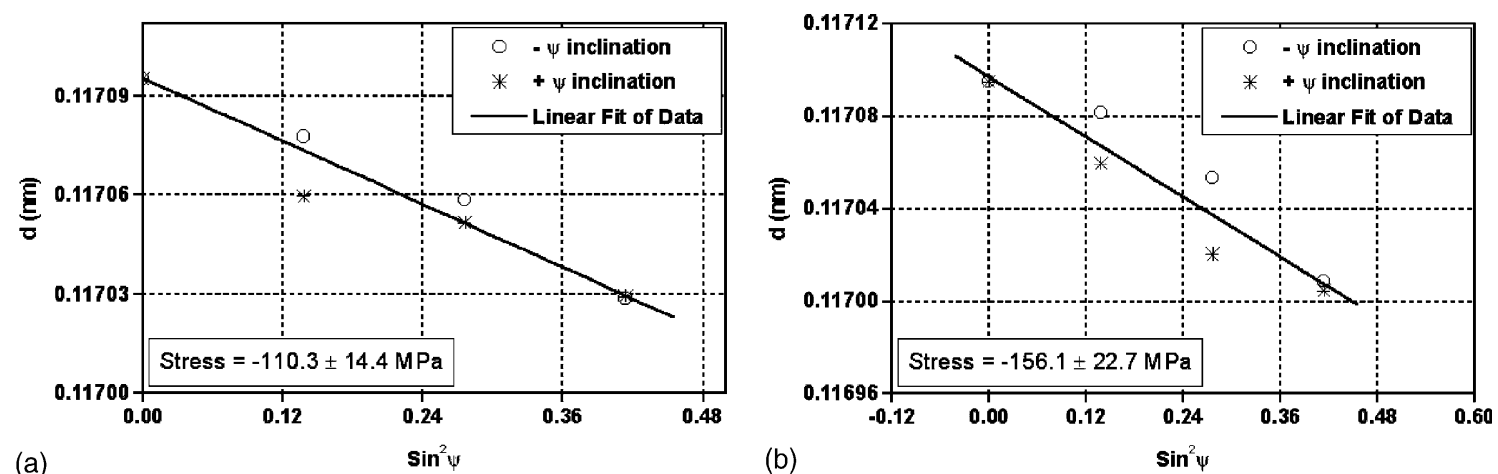

Fig. 5. Estimation of residual stress using multi-exposure side inclination X-ray technique. The graph shows correlation of $\sin ^{2} \psi \mathrm{vs}$ ' $\mathrm{d}$ ' spacing for (a) longitudinal and (b) TDs for Route-1 measured in the BM.
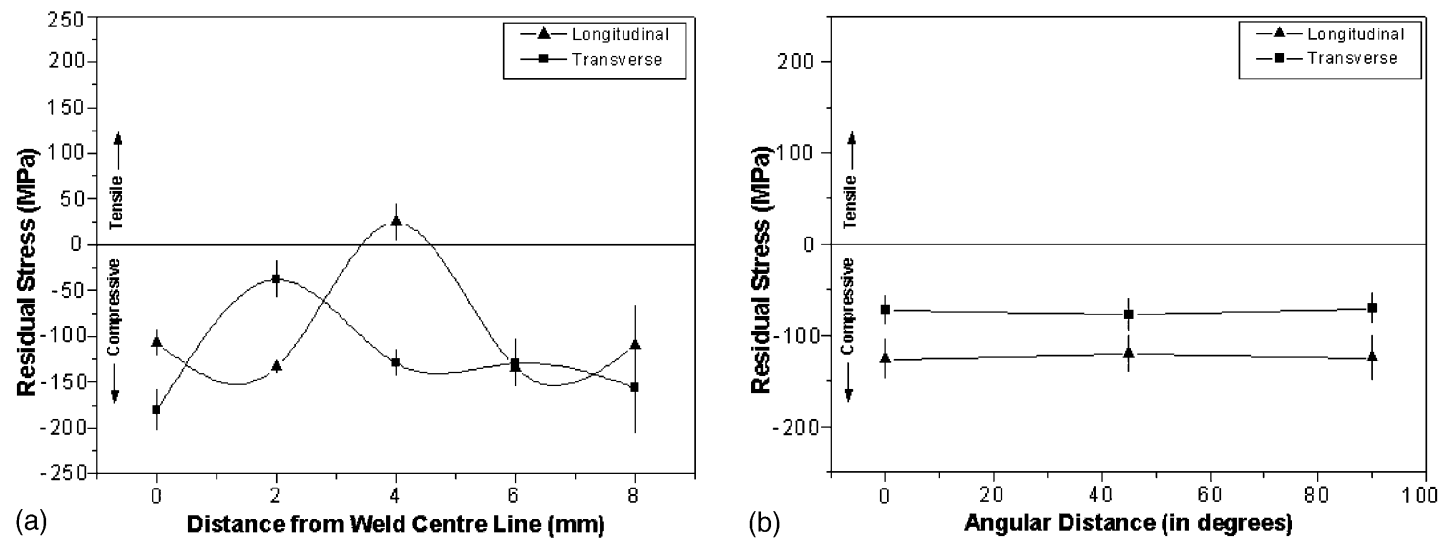

Fig. 6. Variation of residual stress in longitudinal and TDs. (a) Across the WCL for Route-1. Higher residual stress is observed (tensile) in the HAZ and (b) along the circumference in Route-2. The stresses are uniform along the circumference. 
Table 3

Comparison of residual stress values between Route-1 and Route-2 tubes

\begin{tabular}{llcc}
\hline Process & Location & Longitudinal (MPa) & Transverse (MPa) \\
\hline Route-1 & BM (M0) & $-156.1 \pm 22.7$ \\
& 6.0 mm from WCL (M1) & $-129.5 \pm 19.8$ \\
& 4.0 mm from WCL (M2) & $-110.3 \pm 14.4$ & $-129.4 \pm 14.0$ \\
& $2.0 \mathrm{~mm}$ from WCL (M3) & $-134.0 \pm 7.1$ & $-37.9 \pm 25.7$ \\
& WCL (M4) & $+24.6 \pm 20.3$ & $-181.0 \pm 48.4$ \\
Route-2 & Position-A $^{\mathrm{b}}$ & $-133.7 \pm 15.5$ & $-126.3 \pm 21.7$ \\
& Position-B $^{\mathrm{b}}$ & $-107.0 \pm 42.8$ & $-120.7 \pm 20.4$ \\
& Position-C $^{\mathrm{b}}$ & $-72.5 \pm 15.7$ & $-125.0 \pm 24.2$ \\
\hline
\end{tabular}

${ }^{\mathrm{a}}$ Refer Fig. 2 for microstructures at these locations.

${ }^{\mathrm{b}}$ Positions A, B and C are located at an angular displacement of $45^{\circ}$ each on the circumference of the tube.

compressive). In case of Route- 2 the stresses are uniform along the circumference and are fully compressive in both longitudinal and TDs (Table 3).

\subsection{Hydride orientation}

To study the effect of processing on the hydriding behaviour, specimens of $5 \mathrm{~mm}$ length rings from the two routes were charged with hydrogen up to $\sim 200 \mathrm{ppm}$ using Stevert's apparatus [7]. As the solid solubility of hydrogen in this material is negligible at room temperature, all the hydrogen was present in the form of precipitates only. After hydriding, for optical microscope examination, specimens were cut and metallographically prepared from BM, HAZ and FZ for Route-1 and one representative location for Route-2. Optical microscopy was carried out in both longitudinal and TDs to fully characterize the orientation of hydride plates. Fig. 7 gives the hydrided microstructure of the tubes processed using the two routes. From the figure it can be seen that in BM of Route-1 and Route-2, hydrides are oriented parallel to each other along TD. The length of the hydride plates is different in different regions for Route-1. In $\mathrm{BM}$ the plates are parallel but wavy in nature. In HAZ and FZ the orientation of hydrides is markedly different. In HAZ the orientation is random but shorter in length. In the FZ the hydride plates were long and parallel to martensitic laths.

\subsection{Contarctile strain measurements}

To study the mechanical anisotropy developed due to welding in Route-1, contractile strain ratio (CSR) measurements were carried out at room temperature at a strain rate of $1.3 \times 10^{-4} \mathrm{~s}^{-1}$ using Zwick Universal Testing Machine, model 1476. In contractile strain measurements the specimen was given a predetermined plastic tensile deformation along the length of the specimen. The corresponding compressive true strain produced in the other two orthogonal directions, namely, thickness and width directions were, measured. The specimens were prepared with $25.4 \mathrm{~mm}$ gauge length parallel to longitudinal direction of the tube. Three specimens each from FZ, HAZ and BM were prepared. In the parallel portion and across the length of the specimen six markings were made. The distance between two adjacent markings were initially kept at 5 $\mathrm{mm}$ before testing. The specimens were given $2 \%$ and $4 \%$ plastic strain along the length of the specimen consecutively. The changes in the distance between the markings, width and thickness values at the marking were measured for each strain value. From the data obtained, the average true CSRs in thickness $\left(\mathrm{CSR}_{\mathrm{T}}\right)$ and width $\left(\mathrm{CSR}_{\mathrm{W}}\right)$ directions with respect to tensile deformation along the length $(2 \%$ and $4 \%)$ of the specimen were calculated. The measured $\mathrm{CSR}_{\mathrm{T}}$ and $\mathrm{CSR}_{\mathrm{W}}$ are given in Table 4. From the table it can be seen that the $\mathrm{CSR}_{\mathrm{T}}$ and $\mathrm{CSR}_{\mathrm{W}}$ of BM was found to be uniform. In the HAZ, the strain ratios were found to be anisotropic i.e. $\mathrm{CSR}_{\mathrm{T}}$ is $\sim 3$ times that of the $\mathrm{CSR}_{\mathrm{W}}$. This indicates that most of the deformation is accommodated in the thickness direction. Considering the FZ, the observed trend is similar but the degree of anisotropy is reduced from 3 to 1.5 times. However, the value of $\operatorname{CSR}_{T}$ and $\mathrm{CSR}_{\mathrm{W}}$ is found to be higher than that of the other two zones.

\section{Discussion}

The non-uniformity in the residual stress values can be attributed to the welding in the Route-1. Due to the thermal gradients set up during welding process, it is expected to get high magnitude of residual stress in the HAZ. While in the case of Route-2 no such stress gradients is present. During cooling, the FZ undergoes shrinkage in both longitudinal and TD. Whereas adjoining regions of the fused metal resists this contraction. As a result of this, the material acquires tensile residual stress in the HAZ. The magnitude of contraction in longitudinal direction is high, hence stress re- 

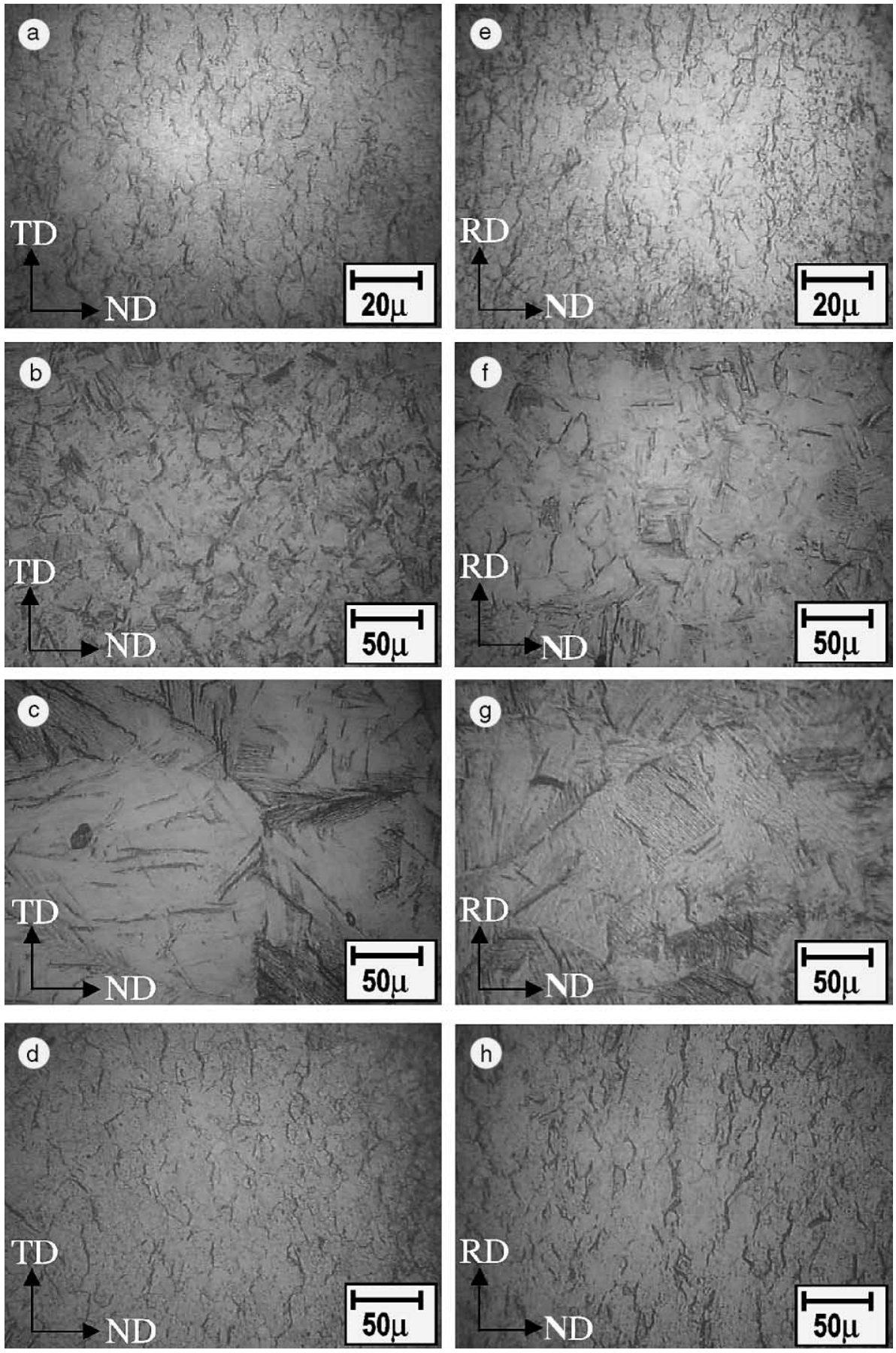

Fig. 7. Microstructure of the hydrided calandria tubes processed using Route- 1 and Route- 2 (ND = normal direction, $\mathrm{TD}=$ transverse direction, $\mathrm{RD}=$ rolling direction). Transverse section: (a) BM, (b) HAZ, (c) WZ, (d) seamless; Longitudinal section: (e) BM, (f) HAZ, (g) WZ and (h) seamless.

versal from compressive to tensile nature in the HAZ is observed. These stresses developed during cooling also influence the texture in the HAZ. In case of Route-2, since there is no thermal gradient like in Route-1, the stresses are uniform and fully compressive in longitudinal and TD. It is well known that only tensile residual 
Table 4

CSRs of calandria tubes processed using Route-1 measured with respect to plastic deformation in the length direction

\begin{tabular}{llll}
\hline Direction & BM & HAZ & FZ \\
\hline $\mathrm{CSR}_{\mathrm{W}}$ & 0.023 & 0.017 & 0.171 \\
$\mathrm{CSR}_{\mathrm{T}}$ & 0.028 & 0.049 & 0.247 \\
\hline
\end{tabular}

stress can lead to stress reorientation of hydrides [8]. Hence it is safe to have compressive residual stress in the material. Because the seamless tubes exhibit uniform compressive residual stress, they will resist any stress related reorientation of hydrides.

The texture variations in the weld region are in line with the previous observations in $\mathrm{Zr}-2.5 \% \mathrm{Nb}$ plate material [9]. It was observed by previous investigators that heat treatments below $923 \mathrm{~K}$ do not affect the texture [10]. The texture development in the HAZ and FZ is due to the occurrence of phase transitions during welding [11]. The reduction in the relative basal pole intensity in the HAZ of the weld in Route- 1 could be due to effect of high temperature exposure during welding in this region. During welding the material in FZ and HAZ are exposed to high temperatures (above $\sim 1170 \mathrm{~K}$ ) in $\beta$ phase region. During rapid cooling from $\beta$ phase, transformation to supersaturated $\alpha$ (martensite) takes place. The orientation relationship, namely, $\left\{\begin{array}{llll}1 & 1 & 0\end{array}\right\}_{\beta} \|$

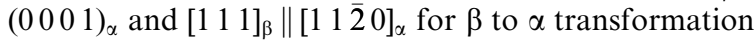
in the presence of residual stresses during cooling results in the observed texture in HAZ and FZ. During BCC $(\beta)$ to $\mathrm{HCP}(\alpha)$ transformation $2 \%$ expansion occurs along

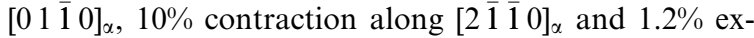
pansion along [ $\left[\begin{array}{lll}0 & 0 & 0\end{array}\right]$ [12]. The residual stresses in HAZ were higher and tensile in nature along RD. The tensile residual stress in RD would favour preferred orientation of [ $\left.\begin{array}{llll}0 & 1 & 1 & 2\end{array}\right]$ in $\mathrm{RD}$ to accommodate expansion during phase transformation. The texture observed in HAZ follows the above arguments where [ [ $\left.\begin{array}{llll}0 & 1 & 1 & 2\end{array}\right]$ direction is found to be close to RD. Since the stresses in the FZ were observed to be lower, it does not favour the preferred orientation as observed in HAZ.

The strain energy minimization in hydrided Zircaloy4 materials orients the hydride plates normal nearly parallel to $\langle 0001\rangle$ direction [13]. Thus the orientation of hydrides strictly depends on the basal pole texture developed in the two routes. As the texture components developed in BM and in Route-2 are similar, the hydride orientations are also identical and found to be lying in TD-RD plane. It may be noted that within a prior $\beta$-grain itself different orientation of martensitic plates are observed. Because of this, the hydrides also follow the same orientation and angular relationship as that of the martensitic plates. The reason for the variation in the size of hydride plates in the three regions can be explained as follows. The martensitic plates are massive and there is a strict orientation relation between the plates, which results in long and straight hydride plates. In the $\mathrm{BM}$, due to the small grain size and minor orientation difference between the grains, broken hydride plates are formed. The major stress during pressure tube failure will be in the TD. Since in seamless tube, hydride platelets orients along TD (which is the stress direction during pressure tube failure) the fracture properties are expected to be unaltered. In case of welded tubes, the orientation of hydrides in the HAZ and FZ is such that the fracture resistance of the tube will be reduced considerably.

In hcp metals, the resolved shear stress and Schmid factor of the various deformation modes varies with inclination of the basal pole to stress direction [14]. The possible deformation mechanisms operating in our case during CSR measurements are either twinning on $\left(\begin{array}{lll}1 & 1 & 2\end{array}\right)$ plane or slip on $\left(\begin{array}{llll}0 & 1 & \overline{1} & 0\end{array}\right)$ plane. The $\left(\begin{array}{lll}0 & 0 & 2\end{array}\right)$ pole figure for BM, indicates that basal pole is oriented at 30$40^{\circ}$ to ND. Thus the angle between the stress direction and basal pole is nearly the same for deformation in width and thickness direction. This implies that the critical resolved shear stresses (CRSS) are the same for both the directions, and thereby, similar strain ratios are obtained. Furthermore, in case of HAZ the basal poles are oriented at $50-60^{\circ}$ to $\mathrm{RD}$. For this orientation the angle between basal pole and stress in thickness and width directions are $\sim 60^{\circ}$ and $90^{\circ}$ respectively. These orientations have lower CRSS when stress is applied in thickness than in width direction. Hence, a higher strain is noticed in the thickness direction. It may be noted that the CSR are observed to be extremely low in both BM and HAZ. This could be justified on the basis of deformation mechanism operating, namely twinning, which yields very low strains. In case of FZ, where the texture is more close to random powder sample, a high strain ratio was observed. It indicates that slip is the dominant deformation mechanism in FZ. In this region the observed strain in both directions are nearly same within experimental error due to near random texture.

A potential method to achieve extra strength for the calandria tube is by increasing the thickness of the weld more than the BM in Route-1 [9]. Even though the weld region has higher strength than the BM in Route-1, the fixed end burst test shows failure of the tubes to be always along the weld on both irradiated and unirradiated tubes. The reason can be attributed to the reduction in the texture strengthening in presence of biaxial stress in the weld region. In the FZ and HAZ, there is a substantial change in texture and microstructure affecting the burst properties of the tube. During welding the FZ was subjected to high temperature and cools rapidly due to heat conduction and additionally by inert gas (Argon), which acts as a cover. A small portion of HAZ is also exposed to elevated temperature in $\alpha+\beta$ phase leading to modification of grain structure. In transverse 
tensile tests, the fracture occurs in the weld region making it most vulnerable for failure during the service. It was shown that the weld reinforcement influences the hoop stress and hoop strain [9]. The burst strength of the calandria tube plays an important role during pressure tube failure. In the case of Route-2, substantial increase in the hoop strain and burst strength with respect to Route-1 was observed. These observations are in line with our tests and the results confirm that weld is the weakest part of the tube in biaxial stressing and supporting the idea that the burst strength of Route- 2 tube is higher than the Route-1 tube. It is clear from the above arguments that Route- 2 is much more advantageous than Route-1 for the processing of thin walled calandria tubes for PHWR applications.

\section{Conclusions}

The present study on the effect of processing route on the properties of the thin walled calandria tubes for PHWR clearly brought in the following conclusions:

1. The tensile properties for both the routes are found to be identical. The microstructure of the BM of seam welded tube was found to be similar to the seamless tube microstructure. Typical martensitic structure is observed in HAZ and FZ.

2. The basal and pyramidal pole texture in the parent material of seam welded tube is similar to seamless material. In HAZ phase transformation from $\beta$ phase region to supersaturated $\alpha$ phase leads to development of a characteristic texture. The maximum lattice expansion during phase transformation is along [ $\left.\begin{array}{llll}0 & 1 & 1 & 2\end{array}\right]$ which gets aligned close to RD.

3 . The analysis of variation of residual stress in longitudinal and TDs shows seam welded tubes have higher residual stress (tensile) in the HAZ. On the other hand seamless tubes have uniform and fully compressive residual stress along the circumference.

4. The hydride orientation in seamless tube is parallel to the TD-RD plane and hence the fracture properties are not seriously affected. In the case of HAZ and FZ the hydrides oriented in thickness direction could reduce the fracture toughness of the component during service.
5. The deformation mechanism acting during the CSR measurements in $\mathrm{BM}$ and $\mathrm{HAZ}$ is twinning on

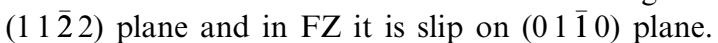
The CSR values of BM and FZ are almost isotropic in width and thickness directions. Whereas in HAZ, anisotropy in the CSR values are observed, the texture observed in the respective zones adequately explains the observed behaviour.

\section{Acknowledgements}

The authors acknowledge assistance by D. Lahiri in residual stress measurements. The authors acknowledge the useful discussions and guidance of Dr C. Gangluy, Chief Executive, Nuclear fuel complex, Hyderabad during the course of this work and kind permission to publish this work. The authors also wish to thank $\mathrm{Mr}$ S.C. Jain, Deputy Chief Executive for his keen interest in the work.

\section{References}

[1] C.E. Ells, C.E. Coleman, C.K. Chow, Can. Metall. Q. 24 (1985) 215.

[2] D.K. Wali, International Congress Tube America, 91, Chicago, 8, 1991, p. 17

[3] C.E. Coleman, 5th conference, ASTM STP 754, 1982, p. 393.

[4] J.B. Vander Sande, A.L. Bement, J. Nucl. Mater. 52 (1974) 115.

[5] L.G. Schultz, J. Appl. Phys. 20 (1949) 741.

[6] H.-J. Bunge, K.-H. Puch, Z. Metallkde. 75 (1984) 124.

[7] R.N. Singh, R. Kishore, S. Roychaudhury, M. Unnikrishnan, T.K. Sinha, P.K. De, S. Banerjee, Santosh Kumar, Technical report no. BARC/2000/E/038, 2000, 20.

[8] M. Leger, A. Donner, Can. Metall. Q. 24 (1985) 235.

[9] J.H. Root, A. Salinas-Rodriguez, Textures Microstruct. 14-18 (1991) 989.

[10] C.E. Coleman, G.L. Doubt, R.W.L. Fong, J.H. Root, J.W. Bowden, S. Sagat, R.T. Webster, 10th conference, ASTM STP 1245, 1994, p. 264.

[11] W.G. Burgers, Physica 1 (1934) 561.

[12] D.O. Northwood, D.T. Lim, Can. Metall. Q. 18 (1980) 441.

[13] L.A. Simpson, M.P. Puls, Metall. Transac. A 10A (1979) 1093.

[14] E. Tenckhoff, ASTM STP 966 (1988) 27. 